\title{
Removing barriers for digital health through organizing ambidexterity in hospitals
}

\author{
Alexander Gleiss ${ }^{1}$ (D) Stefanie Lewandowski ${ }^{1}$ \\ Received: 17 September 2020 / Accepted: 23 March 2021 / Published online: 19 April 2021 \\ (C) The Author(s) 2021
}

\begin{abstract}
Aim Hospitals noticeably struggle with maintaining hundreds of IT systems and applications in compliance with the latest IT standards and regulations. Thus, hospitals search for efficient opportunities to discover and integrate useful digital health innovations into their existing IT landscapes. In addition, although a multitude of digital innovations from digital health startups enter the market, numerous barriers impede their successful implementation and adoption. Against this background, the aim of this study was to explore typical digital innovation barriers in hospitals, and to assess how a hospital data management platform (HDMP) architecture might help hospitals to extract such innovative capabilities.

Subject and methods Based on the concept of organizational ambidexterity (OA), we pursued a qualitative mixed-methods approach. First, we explored and consolidated innovation barriers through a systematic literature review, interviews with 20 startup representatives, and a focus group interview with a hospital IT team and the CEO of an HDMP provider. Finally, we conducted a case-study analysis of 36 digital health startups to explore and conceptualize the potential impact of DI and apply the morphological method to synthesize our findings from a multi-level perspective.

Results We first provide a systematic and conceptual overview of typical barriers for digital innovation in hospitals. Hereupon, we explain how an HDMP might enable hospitals to mitigate such barriers and extract value from digital innovations at both individual and organizational level.

Conclusion Our results imply that an HDMP can help hospitals to approach organizational ambidexterity through integrating and maintaining hundreds of systems and applications, which allows for a structured and controlled integration of external digital innovations.
\end{abstract}

Keywords Digital innovation $\cdot$ Digital health $\cdot$ Hospital innovation $\cdot$ Innovation barriers $\cdot$ Organizational ambidexterity

\section{Introduction}

Digital transformation massively affects the value creation, value proposition, and customer interaction models of companies and entire branches. This also applies to the healthcare sector. Here, digital technologies have huge potential to enhance healthcare quality and reduce costs but face a multitude of adoption barriers (Agarwal et al. 2010; Pousttchi 2017; Pousttchi et al. 2019a). Healthcare is a complex, regulated

Alexander Gleiss

gleiss@uni-potsdam.de

1 University of Potsdam, August-Bebel-Str. 89, 14482 Potsdam, Germany and fragmented sector. Digital technologies diffuse from multiple directions (Chan et al. 2004; Fichman et al. 2011; Gleiss et al. 2021) and aim to improve the healthcare performance (Lapāo 2019), allow for new business models (Menvielle et al. 2017), or possibly reshape the relationship between patients and healthcare providers (Brucher et al. 2018). Thus, they provide new ways and tools for the detection, diagnosis, and therapy of diseases as well as transforming entire processes of and around healthcare (Gimpel and Röglinger 2015; Pousttchi et al. 2019b). Altogether, innovative and disruptive technologies might conceivably revolutionize the entire healthcare sector with remarkable consequences for providers, patients, and other stakeholders (Christensen et al. 2017) — and there are yet technologies to follow which might help hospitals to become "smarter" (Bogdan 2018; Williams 2019). However, practical insights indicate that hospitals noticeably struggle with the 
massive changes around (Dash et al. 2019; Eddy 2020). Hospitals have to manage a plethora of (partly critical) IT systems and applications and need to comply with the latest standards and regulations for IT and patient security. Therefore, it is challenging to simultaneously manage the existing IT systems and continuously explore new technologies. To find a remedy for this problem, hospitals might consider integrating technologies from digital health startups, which are seen as one important driver of technology diffusion in healthcare (Chowdhury 2012; Villegas 2019).

Against this background, the aim of this paper is to explore how a hospital data management platform (HDMP) might support hospitals to leverage innovative capabilities by integrating digital technologies. We refer to the concept of organizational ambidexterity $(\mathrm{OA})$ and pursue a qualitative mixedmethods approach with three major steps and results: (1) To explore and validate typical DI barriers in hospitals, we conducted a literature review on innovation barriers in hospitals with follow-up interviews with 20 representatives from digital health startups. (2) To assess the mitigating effects of the HDMP, we conducted a focus group session with a hospital IT team and the CEO of the HDMP provider. (3) To theorize on the potential impact of DI in hospitals, we conducted a case-study analysis of 36 digital health startups and applied the morphological method to synthesize our findings from a multi-level perspective. The rest of the paper is structured as follows. In the next section, we provide background information on the referred theory and the HDMP project. Then we describe our methodical approach, before we present and analyze our findings in the subsequent section, where we assess how an HDMP might help to overcome barriers and leverage possible effects through the integration of digital innovations in hospitals. Finally, we provide a conclusion and outlook.

\section{Background}

\section{Related work: Digital innovations in hospitals}

The healthcare sector is undergoing a massive digital transformation these days as progress in the field of digital health illustrates (Agarwal et al. 2010). In this context, digital health means the usage of ICT in healthcare (Gersch and Wessel 2019) and affects organizations at all dimensions of digital transformation, namely value creation, value proposition, and customer (i.e., mostly patients) interaction (Pousttchi 2017) as shown in Fig. 1.

In terms of value creation, digital technologies can help healthcare service providers to implement completely new processes or organizational structures (Bygstad et al. 2017; Denner et al. 2018). Hence, they can likewise improve treatment and reduce costs (Ghosh et al. 2018). For instance, sensors and machine-learning-based algorithms can help to detect diseases or disorders (Shen et al. 2013; Hussainy et al. 2017). In terms of value proposition, digital health paves the way for entirely new services or business models (Thambusamy and Palvia 2011), both for traditional healthcare providers and new tech players which enter the promising market. For instance, healthcare providers can offer telemedicine services for remote diagnoses and consultation (Miscione 2007), electronic health records (EHR) (Xie et al. 2019), or mobile devices and applications for the patients (Gurtner 2014). In terms of customer interaction, healthcare service providers can exploit these applications and devices for new forms of patient interaction and data generation to address patients' expectations and needs, such as on-demand healthcare solutions (Gleiss 2020).

A crucial factor is the successful implementation of digital innovations, which implies the carrying out of new combinations of digital and physical components to develop novel products (Yoo et al. 2010). In contrast to the plethora of research in the field of digital innovation (e.g., Yoo et al. 2012; Hund et al. (2019), comparatively few contributions examine the healthcare sector (Kohli and Melville 2019). Vom Brocke et al. (2007) designed a clinical process mapping methodology to support information systems innovation in a healthcare context that requires the integration of relevant stakeholders. In line with this, Scheplitz et al. (2019) have highlighted the critical role of healthcare information systems in digital innovation projects regarding processes, information flows, applications, and IT infrastructures. Especially, such information infrastructures seem crucial for the successful implementation of digital innovations (Grisot et al. 2013). Other contributions have explored success factors and reasons for failure of digital innovation projects in healthcare (e.g., Schubert 2004; Teoh 2010; Przybilla et al. 2018; Scheplitz et al. 2019). Further research focuses on the general diffusion of digital innovations in healthcare (Chan et al. 2004; Greenhalgh et al. 2004), especially by harnessing new digital technologies (Brown et al. 2014; Fernández 2017) such as telemedicine (Steinhauser 2019) or big data (Ambigavathi and Sridharan 2018). Altogether, startups bear the potential to revolutionize entire industries and might also play an important role in innovating healthcare (e.g., Chowdhury 2012; Mandl et al. 2015; Christensen et al. 2017; Garbuio and Lin 2019). Digital technologies in hospital care require collaborative innovation among multiple actors both within and beyond hospitals; therefore, peripheral actors such as clinicians or technology providers can bring in resources for both innovation and value creation (Aanestad et al. 2019). Particularly, living labs can foster frugal digital innovation based on open collaboration of different actors and stakeholders (Sahay et al. 2018). In addition, although incumbent firms can benefit from collaborating with startups (Kohler 2016; Islam et al. 2017), research has not sufficiently explored such opportunities for healthcare service providers such as hospitals. 
Fig. 1 Dimensions of digital transformation (Pousttchi 2017)

Customer Interaction Model

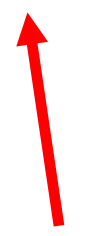

\section{Digital Transformation}

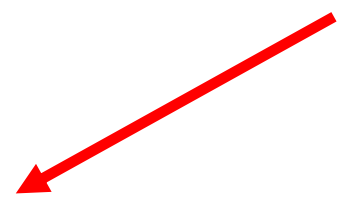

Value Creation Model

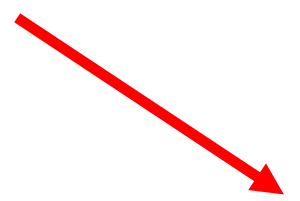

Value Proposition Model

\section{Organizational ambidexterity of healthcare organizations}

Hospitals need to manage hundreds of (partly critical) systems and applications that are used simultaneously and routinely (Bradley et al. 2012). Consequently, IT managers in hospitals are busy with the smooth run, maintenance, and support of their IT landscape, which makes it complicated to continuously search for and implement new digital applications. They rather focus on exploiting their existing digital technologies than exploring new digital innovations to integrate. This dilemma is broadly covered by the concept of organizational ambidexterity (OA), which was introduced by Duncan (1976). He refers to an organization's ability to implement dual structures for managing the balance of alignment and adaptation as he found that organizations forfeit innovativeness and - in the long-runcompetitiveness if they only concentrate on improving their efficiency. Over time, this concept has rooted in the consensus that $\mathrm{OA}$ implies the ability of a firm to simultaneously explore and exploit technologies (O'Reilly and Tushman 2004). Only those companies that are able to conduct both explorative and exploitative action are capable of incremental and radical innovation (Gibson and Birkinshaw 2004; Rothaermel and Alexandre 2009). Further research has extended this understanding of ambidexterity as a continuous and simultaneous balance of such activities in trade-off situations, while managing and harnessing these trade-offs helps improving the firm's performance (Rothaermel and Alexandre 2009; Wolf 2019) both on an organizational and individual level (Wolf and Lüttenberg 2020), as shown in Fig. 2.

Although there is plenty of theoretical research on OA, only a few contributions have applied this concept for studying a company's sourcing strategy. Accordingly, companies need to source new technologies both internally and externally to remain innovative and competitive at the same time (Rothaermel and Alexandre 2009; Raisch and Birkinshaw 2008), and digital infrastructures can be foundational for ambidextrous innovation processes (Montealegre et al. 2019), especially in healthcare settings (Abraham and Junglas 2011).

Only a few contributions have adopted the notion of $\mathrm{OA}$ in the context of healthcare. Tarafdar and Gordon (2007) illustrate from a resource-based view how OA enables healthcare companies to recognize the strategic importance of innovation, and apply appropriate long-term evaluation criteria for projects. Bodwell (2011) demonstrates how OA is positively related to quality, and Kwak et al. (2016) show that process ambidexterity in healthcare organizations enhances team activities and performance. Burgess et al. (2015) examine the contextual and personal circumstances that enable middle managers to forge compromises between exploration and exploitation. Koster and van Bree (2018) found that OA in a hospital strengthens collaboration through increased interdependency, albeit hospitals rather switch between innovation and exploitation instead of being continuously ambidextrous. In contrast, Kizito and Kahiigi (2018) reveal how ambidextrous structures can be implemented by profound IT governance.

Altogether, organizations can take huge advantage of implementing dual structures to explore and exploit digital innovation and technologies likewise. In this context, externally integrated innovations can play a crucial part in the future innovativeness and competitiveness of healthcare organizations. Thus, the question remains how hospitals can remove barriers to extract advantage from digital health innovations by approaching ambidextrous structures. Against this background, we seek to explore how an HDMP can support such endeavors.

\section{The "health engine" project in a German hospital}

We accompanied the implementation of the "Health Engine," a hospital data management platform (HDMP), at a large hospital group in northern Germany. The hospital group has nine hospitals (with a total capacity of 2200 beds and $6700 \mathrm{em}-$ ployees) and runs 150 merely interoperable applications (50 
Fig. 2 Service ambidexterity framework (Wolf 2019)

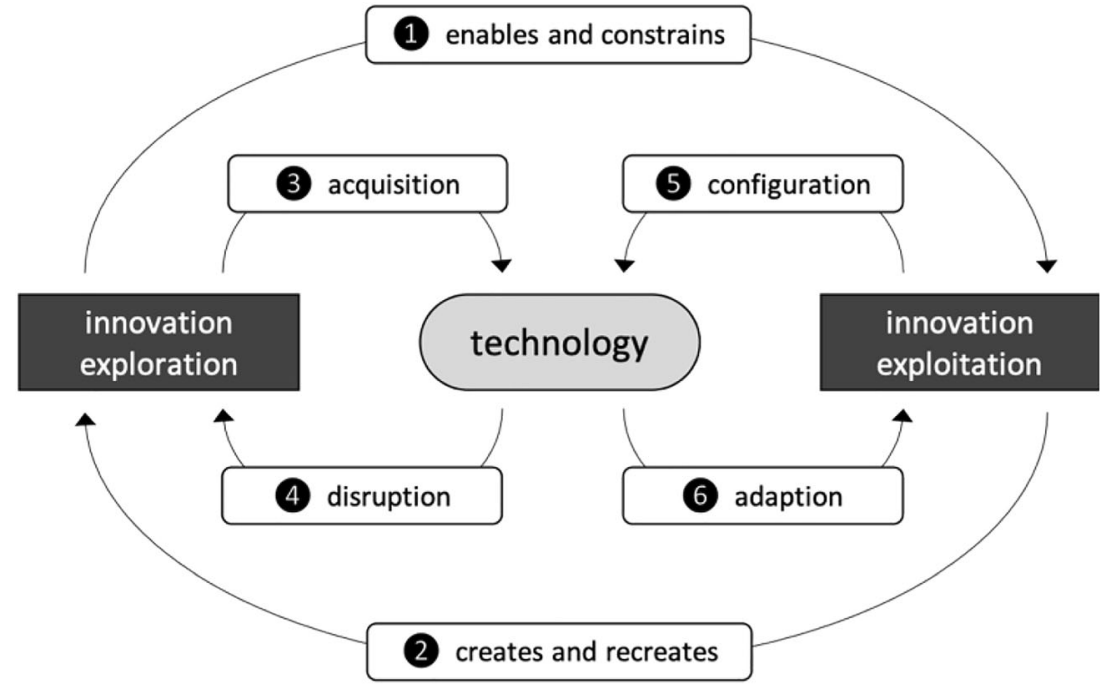

applications with patient data). The HDMP has been developed by the Swiss software company "the i-engineers" and is widely used by Swiss hospitals. The HDMP is a healthcare-specific data-warehouse architecture with three tiers for comprehensive enterprise information management in hospitals. The database tier contains a performant and reliant Oracle database with PL/ SQL, the object-oriented data model follows a clinical logic (structures and processes) and is compliant with IHE, HL7, and DICOM. The application tier provides processing mechanisms through a Java-based Spring Boot microservice framework that includes a REST backend interface (for clients and apps) and components for communicating with external services, peripheral systems, file storages, and the database tier. Here, the HDMP provides several APIs. The client tier provides the front-end user interface based on HTML5 and Angular, which also allows for mobile applications.

The implementation entails three major tasks. First, a clear data model for the HDMP repository needs to be defined, both semantically and syntactically. This is important, as future changes might be more effortful. Ideally, the data model contains a master patient index (MPI), which allows for a crosssectoral harmonization of patient and case records. Second, each system has to be connected separately, which requires manual mapping of the data attributes in the databases and communication servers, and programming of the interfaces between the systems and the HDMP. At this, the hospital and the provider had to work closely together. Third, the systems legacy data has to be replicated in the HDMP for mirroring. For instance, the integration of a bed sensor system to monitor patients' vital data took 14 person-hours, while the HIS integration took several weeks. Once implemented, the HDMP can be configured to retrieve and transfer data from and to many healthcare-related application and information systems in real time, such as HIS, PACS (picture archiving and communication system), as well as generic enterprise systems, such as ERP systems or office applications.
Furthermore, graphical user interfaces (GUI) can be programmed for the staff or patients, combining data from different sources. At this level, basic functions can be integrated (e.g., print, PDF converting, text recognition, search, signature, recording). What is more, various data can be stored, managed and archived (e.g., patient, staff, or medical data), which allows for complete data backups. Thus, data is archived redundantly and completely owned and accessible by the hospital. Figure 3 provides an overview of the HDMP architecture and the interfaces. The technical and semantical integration of all resources enables the design of personalized applications (including authorization and access management). For instance, a patient portal can be developed and attached. Consequently, the HDMP structure can be mapped onto the hospital-specific processes and organization structures. As the HDMP is compliant with international healthcare standards (DICOM, HL7, IHE), digital communication with external stakeholders (e.g., healthcare service providers, insurances) is facilitated.

\section{Methodical approach}

To address and frame our research question, we apply a mixed-methods approach consisting of three phases: exploration, consolidation, and synthesis (see Fig. 4).

(1) The exploration phase answers the purpose of identifying barriers for digital innovations in hospitals. At this phase, we first conducted a systematic literature review to gather a representative coverage (Cooper 1988; Webster and Watson 2002) by an abstract and keyword search in relevant scientific databases (AISel, IEEE, EBSCOhost, ScienceDirect, Springer, Wiley) for the expression "("barrier*”) AND ("digital*" OR "technolog*") AND ("hospital*" OR "clinic*" OR 


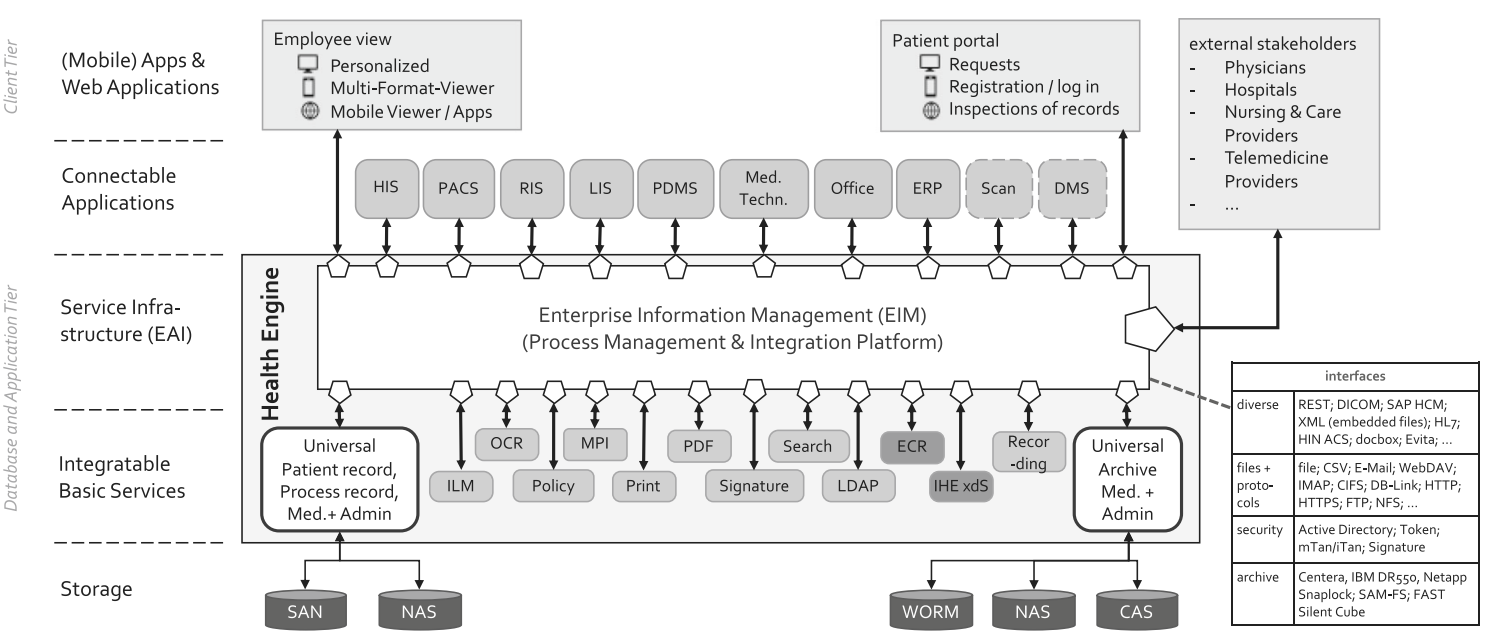

Fig. 3 Architecture of the HDMP "Health Engine" (see appendix for abbreviations)

“*health*)," resulting in 952 potentially relevant papers. We then selected those contributions with a clear relation to our research question by reading the abstracts and removing duplicates (n: 56) and full texts of the remainders, which led to a total of 27 relevant research papers. We analyzed these papers to derive and define typical barriers for hospital innovation through an inductive coding method following the guidelines from Mayring (2000). Second, we sought for validation of the identified barriers from the supply side (i.e., digital health startups). Here, we conducted standardized, structured telephone interviews with representatives from 20 startups (e.g., CEOs, sales agents). Then we specifically posed open-ended questions to elaborate on their experiences with business contacts and negotiations with hospitals (Patton 2015, p. 638). Each interview took 20-30 min, the answers were protocolled, coded, and specifically assigned to the barrier types. Altogether, we identified six superordinate barrier types (technological, organizational, behavioral, financial, legal, and structural) as a basis for the following two phases.
(2) The consolidation phase serves a dual purpose: For one thing, we sought for validation of the identified barriers from the demand side (i.e., hospitals). For another thing, we aimed to assess the mitigating role of an HDMP in this context. Thus, we conducted a three-hour focus group interview for evaluation (Patton 2015, p. 697) with three participants: the hospital CIO (who is in charge of all digital health projects in the hospital facilities), one of his employees, and the CEO of the HDMP provider. Then we elaborated on the participants' views and experiences of integrating innovations in hospitals and discussed how the HDMP could mitigate the identified barriers from the exploration phase. The responses were protocolled and assigned to these barriers. As a result of the consolidation phase, we could both substantiate the barriers and assess if and how an HDMP can mitigate them.

(3) In a final synthesis phase, we aimed to explore the potential benefits of digital innovations in hospitals once barriers are mitigated or overcome. Here, we first elaborated on impact potentials by conducting a qualitative comparative case-study analysis with 36 digital health

\begin{tabular}{|c|c|c|c|}
\hline phase & (1) exploration & (2) consolidation & (3) synthesis \\
\hline aim & $\begin{array}{l}\text { identifying and validating } \\
\text { DI barriers in hospitals }\end{array}$ & $\begin{array}{l}\text { assessing the mitigating } \\
\text { effects of an HDMP }\end{array}$ & $\begin{array}{l}\text { conceptualizing the } \\
\text { impact of DI in hospitals }\end{array}$ \\
\hline methods & $\begin{array}{l}>\text { literature review } \\
>\text { interviews w/ } 20 \\
\text { startup employees }\end{array}$ & $\begin{array}{l}\text { focus group interview } \\
\text { w/ hospital IT team }+ \\
\text { CEO of HDMP provider }\end{array}$ & $\begin{array}{l}>\text { case study analysis } \\
\text { w/36 startups } \\
>\text { morphological analysis }\end{array}$ \\
\hline
\end{tabular}

Fig. 4 Research design 
startups from a regional healthcare cluster (see Table 1). Case studies are fruitful to explore and conceptualize barely explained, complex phenomena from empirical data (Benbasat et al. 1987). For a careful and purposeful case selection, our sample focuses on typical group characteristics of digital health startups with a deliberate balance of homogeneity and variation to identify and illuminate important group patterns (Patton 2015, p. 428; Yin 2009).

We applied complementary concepts to these cases to understand, analyze, and compare the innovative capacity and impact potential of each case. Here, we refer to businessrelated concepts, as resource-based view (Barney 2001), process and value creation (Porter 1985; Hammer and Champy 1993), digital transformation (Pousttchi et al. 2019a), and stakeholder value (Donaldson and Preston 1995). We also applied health-related concepts such as healthcare cycles (Fiechter and Meier 1998; Bergman et al. 2011; Knöppler et al. 2016) or interoperability models (Sunyaev et al. 2010). In this way, we derived and determined the scopes of beneficiaries, impact areas, and impact causes for each innovation.

Finally, we condensed our findings into conceptual artifacts. Specifically, we first applied the morphological method to arrange and categorize our findings within the barriers and impact potentials. This method is a highly systematic approach for structuring multi-dimensional problems and involves the identification and definition of a problem's essential characteristics as well as the assignment of their relevant instances. The aggregate of all characteristics and instances is represented by a morphological box, which allows for structured analysis and comparison of complex phenomena (Zwicky 1966; Ritchey 2013). Hereupon, we conceptualized our findings into a more generic framework from a multi-level perspective to emphasize the relationships. Multi-level research enables an integrated understanding of phenomena that unfold across levels in organizations and systems. Micro phenomena are embedded in macro contexts and macro phenomena often emerge through the interaction and dynamics of lower-level elements (Burton-Jones and Gallivan 2007).

\section{Results: Barriers for digital innovation in hospitals and the mitigating role of an HDMP}

\section{Exploration phase: Identifying barriers for digital innovation}

Digital innovations often face a multitude of barriers, especially in healthcare. Within this sub-section, we present and discuss the findings of our exploration phase, consisting of a literature review and 20 interviews with digital-health startup representatives. Altogether, we aggregated all barriers into six superordinate barrier types: technological, organizational, behavioral, financial, legal, and structural barriers. For each barrier, respective insights from the interviews are referred to by “\#” and their number (as per Table 1).

Technological barriers The available literature discusses technological barriers on different levels ranging from the IT Infrastructure of a country to functionality problems of the service (Akhlaq et al. 2016; Gajarawala and Pelkowski, 2020. As McLachlan et al. (2019) point out, one issue is a lack of interoperability among new and legacy systems (due to missing APIs). This claim is supported by one startup, which mentioned that it is often difficult to connect their technologies with the core systems of hospitals (\#6). Low compatibility might be another critical barrier, particularly if the offered service does not work on available devices or OS (Gagnon et al. 2012). Furthermore, not all healthcare facilities can provide the required network access (Harst et al. 2019), which was confirmed by the startups (e.g., \#27). A lack of data often leads to poor data integrity and quality, which in turn adds up to a low reliability and a poor foundation for superior data-based services (Frederix et al. 2019). One startup has faced troubles in gaining the required information that make their innovations work at all (\#15). Functionality problems imply difficulties in bringing proof of the technical feasibility, system efficiency, or technological capabilities (Frederix et al. 2019). The overall technological complexity refers to implementation and maintenance of digital services (Lim and Anderson 2016; Harst et al. 2019). The complexity is highly dependent on the level of required integration within the hospitals' systems in terms of required data (semantics and syntactics), available APIs, and workflow alignment, which often have to be harmonized with existing systems. Given the variety of systems throughout hospitals, some of the inquired startups prefer the provision of a web-based service over connecting to the core systems of a hospital via APIs, if possible (e.g., \#6).

Organizational barriers Other barriers originate from processes and structures at the organizational level. For instance, Stamatian et al. (2013) studied barriers resulting from workflow deficiency. Such deficiencies affect decisionmaking processes that exclude the actually concerned user groups (MacNeil et al. 2019). Additionally, there can be a lack of integration in the clinical work, resulting in more work for the users instead of reducing the workload (Palacholla et al. 2019; Graetz 2020). Issues around physicians include that they simply have no time for non-patient related concerns (Stamatian et al. 2013; Nohl-Deryk et al. 2018). This claim belongs to the barriers most mentioned by the startups (\#2, \#4, \#6, \#12, 14, \#22, \#24). Hierarchical deficiency includes 
Table 1 Overview of analyzed cases (digital health startups)

\begin{tabular}{llll}
\hline No. & Core value proposition & No. & Core value proposition \\
\hline 1 & app to diagnose deep vein thrombosis & 19 & chatbot application for patient care \\
$* 2$ & system to monitor and control the usage of disinfection agents & 20 & health IS for small hospitals with a digital patient record \\
$* 3$ & mobile app for the patient-nurse communication & 21 & wearable and app to record and analyze palsy patients' moves \\
$* 4$ & software for automating cancer medication plans & $* 22$ & app for directly booking consultation appointments \\
5 & software to automate the documentation of medical reports & $* 23$ & app and cloud to securely store medical data \\
$* 6$ & mobile app to support patients with chronic diseases & $* 24$ & app for automatic individual therapeutic exercise plans \\
$* 7$ & mobile app for gait pattern analysis to prevent falls & 25 & software to detect accounting errors for medical services \\
8 & platform for patient pathway automation & $* 26$ & sensor-based UV rays to kill germs \\
9 & app to capture patient-related outcome measures & $* 27$ & sensor-based adhesive wearable to monitor patients \\
10 & platform and apps for gynecology wards and patients & $* 28$ & gamification-based platform to support therapeutic exercise \\
11 & health IS plugin to modify or personalize the user interface (UI) & $* 29$ & healthcare data management and transfer platform for patients \\
$* 12$ & mobile app for nurses to automatically record services & $* 30$ & ML-based system for the prognosis of genetically determined diseases \\
13 & platform for psychological online seminars and consultation & 31 & smart exoskeleton to support the lower back of caregivers \\
$* 14$ & platform for hospitals to find suitable after-care providers & $* 32$ & mobile app for an acoustic feedback of a movement's intensity \\
$* 15$ & device and app to record, archive and analyze long-term ECG & $* 33$ & P2P technology for secure end-to-end video councils \\
16 & device for insulin injection and app for blood-glucose analysis & 34 & video system to include therapeutic exercises in daily routine \\
$* 17$ & technology for 3D imaging from ultrasound & 35 & website to enroll doctors for relevant training courses \\
18 & cyber-physical robotics system to support surgeries & $* 36$ & monitoring system to support individual home-based aftercare
\end{tabular}

* representatives of marked startups also participated in a telephone interview

missing top-management support, low change management, and scattered key players that operate independently within the organization causing unclear roles and responsibilities (Mason et al. 2017; Mohamadali and Zahari 2017a; Harst et al. 2019). The startups confirmed that such opacities are a major barrier for them (\#2, \#4, \# 26) and so are long decisionmaking processes (\#2, \#26). At last, there are also cultural barriers which evolve around the issue of differences in adopting and accessing digital resources (Lim and Anderson 2016; Otto and Harst 2019). Especially, a cultural resistance toward (technology-induced) changes might hamper the adoption or implementation of digital innovations and requires adequate change management approaches (Lluch 2011).

Behavioral barriers Many barriers occur on an individual, i.e., staff or patient-related, level. According to Frederix et al. (2019), such individual barriers include the attitude toward technology or devoid intrinsic motivation and knowledge. Following Gagnon et al. (2012), a negative attitude toward new technologies often stems from a lack of incentives or, especially in terms of elderly patients, low perceived usefulness and confidence in technology in general (Gagnon et al. 2012; Frederix et al. 2019). Plus, some startups experience a mistrust toward their technologies, such as AI (\#15). Furthermore, available research states missing acceptance of digital health innovations (Holden and Karsh 2010), particularly due to missing or wrong information. Fear turns out to be another barrier in healthcare, especially fear of more transparency about the medical processes, which results in a loss of control and strengthens the patient's position (Stamatian et al. 2013; Nohl-Deryk et al. 2018; Harst et al. 2019). Fear and doubts also arise from missing social contact when switching to digital solutions such as online consultations (\#36). Low motivation to explore new technologies is another identified barrier (Stamatian et al. 2013; \#4), and so is knowledge, where a lack of business education of healthcare professionals often leads to ignorance toward anticipated healthcare benefits (Malekzedath et al. 2018). This was confirmed by a startup stating that the benefit of the innovation was not recognized (\#4). In line with that, Apathy and Holmgren (2020) identify knowledge barriers resulting from insufficient training opportunities for employees on new technologies.

Financial barriers Monetary problems concerning digital innovations range from verification issues to missing public funds. Lim and Anderson (2016) stated that the missing proof of RoI is a risk for healthcare providers, and thus a market-entry barrier for startups. A similar problem is the uncertain refundability of digital innovations (Vannieuwenborg et al. 2015; Lim and Anderson 2016; Frederix et al. 2019; Soobiah et al. 2020). Among others, Desveaux et al. (2019) identify the problem of few public funds and missing governmental financial support for digital innovations (Ajami and Arab-Chadegani 2013; Mason et al. 2017; Mohamadali and Zahari 2017; Malekzadeh et al. 2018; Harst et al. 2019). This 
problem was also stated by the interviewed startups (e.g., \#3, \#26). Costs are a barrier, because high implementation costs often represent a deterrent, and the amount of lifecycle costs is sometimes difficult to estimate (Gagnon et al. 2012; \#4). Plus, there is a general lack of (external) financial incentives for the introduction and use of digital innovations in healthcare (Nohl-Deryk et al. 2018).

Legal barriers Data security and privacy issues are relevant for both users and providers. Patients' concerns about the usage of their data are increasingly rising (Gagnon et al. 2012; NohlDeryk et al. 2018). If these two barriers are unclear or addressed insufficiently, trust in these services decreases (Zaidan et al. 2011). Plus, healthcare providers have to ensure legal compliance of their IT systems, especially in terms of the General Data Protection Regulation (GDPR) and the patient security law (Blobel and Ruotsalainen 2019). Also, there are reliability concerns about the performance or testing procedures of new innovations and their compliance with legal requirements (Vannieuwenborg et al. 2015; Palacholla et al. 2019). Altogether, there are several difficulties in understanding and implementing legal requirements. Moreover, differences in legislation at federal and state levels even increase the legal complexity (Apathy and Holmgren 2020).

Structural barriers On a more generic level, structural barriers can hamper the implementation and diffusion of digital innovations in healthcare. Owing to the very nature of health systems, healthcare providers face strict regulation (Ajami and ArabChadegani 2013; Zakaria and Mohd Yusof 2016; Apathy and Holmgren 2020). Such structural barriers are oftentimes beyond a hospital's sphere of influence and include issues of standardization, certification, approval, and cooperation. Hence, the use of new technologies often rather becomes a burden than an improvement (Graetz 2020). At the same time, existing regulatory guidelines or measures can be unclear and unbalanced. Plus, actors in the healthcare system only make slow progress in comprehensive standardization, which results in IT incompatibility, media disruptions, poor processes, and insufficient usability of staff or patient applications (Ajami and ArabChadegani 2013; Nohl-Deryk et al. 2018). Furthermore, certification and approval processes (e.g., clinical evidence, certification marks, marketability) can hamper the introduction of new technologies (Anderson 2007). While missing certification excludes the technology's usage directly, missing approval complicates the billing mechanisms for digital services - particularly, if the healthcare service is paid by an insurance (Harst et al. 2019). Additionally, the startups stated poor cooperation between the healthcare providers and other stakeholders in the healthcare system (e.g., payers, medical associations) as an additional barrier (e.g., \#29, \#33).

Altogether, barriers arise at different levels and can either stem from shortcomings of individuals such as staff or patients (behavioral), of the hospital as a social system (organizational, financial, technological, legal), or of the healthcare system at large (legal, structural). We condensed all identified and aggregated barriers into a morphological box (see Fig. 5).

\section{Consolidation phase: Mitigating barriers through an HDMP}

In a second step, we sought to explore to what extent the implementation of an HDMP can mitigate some of the identified barriers. Thus, we conducted a focus group interview with the hospital CIO, one of his employees, and the CEO of the HDMP provider. We present and discuss the findings in this sub-section.

With respect to technological barriers, the HDMP can mitigate all barriers except a lack of network access according to the interviewees. Once implemented and configured properly, the HDMP can access, compute and transfer all relevant information systems, applications and databases, and thus might solve issues regarding interoperability, compatibility, and data retrieval. What is more, the hospital is able to provide only such data that is required by the startup, and thus enhance functionality and reduce technical complexity. In terms of organizational barriers, the HDMP can employ the IT systems to optimally support the actual processes and thus reduce workflow deficiency of new technologies to be integrated. Particularly, the medical controlling unit has integrated access to data from different sources relevant for billing processes. If new technologies work more seamlessly, cultural resistance might diminish as well. For instance, the medical staff agreed with the bed sensor system as the vital data was integrated in the GUI of the used systems. However, the HDMP might probably not mitigate hierarchical deficiencies. It might help to shorten decision-making processes, but not in terms of technology sourcing.

This is different with behavioral barriers: If new technologies are integrated user-friendly, work seamlessly, and provide added value, the staff's attitude, acceptance, and motivation might rise to use these technologies. Especially, if the technologies are intuitive or help improve healthcare services, fear or knowledge gaps might become less important. These effects could be observed in a project in which patients have been equipped with wearables where the medical staff could manage and monitor the health-related data. Contrarily, the HDMP might hardly help to mitigate all financial barriers, albeit some financial risks and costs might be indirectly alleviated through a simpler integration of new technologies, which allows easy testing and piloting. Hence, the RoI, costs, and incentives of new innovations are rather unconcerned, while refundability and the acquisition of public funds for new digital therapies and diagnostics might be accelerated through a faster and simpler integration.

The HDMP might help hospitals to mitigate some legal barriers. While issues with security and privacy might even 


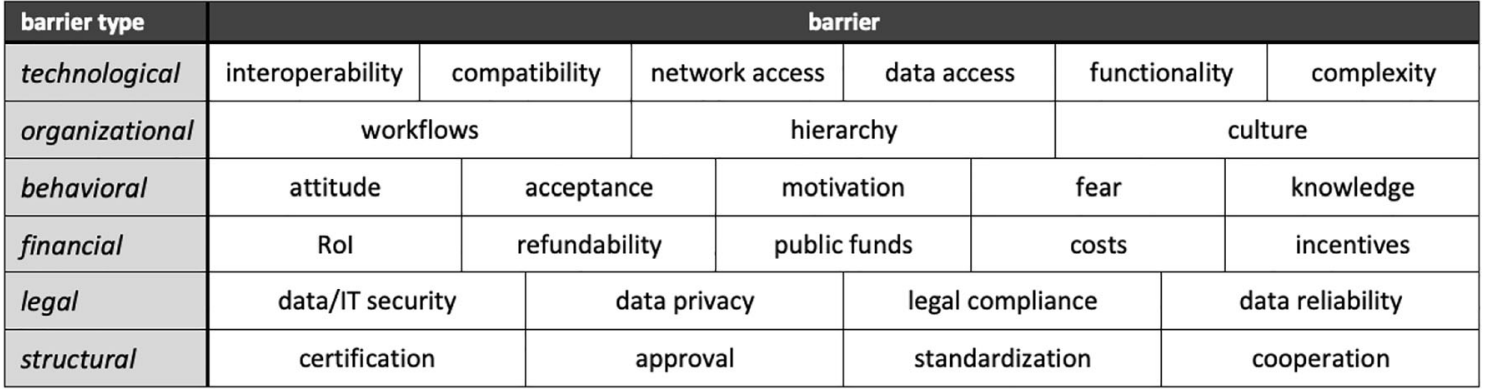

Fig. 5 Morphological box of typical barriers for digital healthcare innovations

increase through the high degree of interconnectedness, a single point-of-failure architecture, and data redundancy, legal compliance and data reliability might be enhanced through a comprehensive documentation and the data sovereignty of the hospital. In terms of structural barriers, the HDMP might only help indirectly. Clinical trials might be conducted and documented more seamlessly (at least from a technical point of view). However, this does not affect the decision processes about certification and approval. In addition, although the HDMP is compliant with common standards in healthcare, it will not solve standardization problems within the entire healthcare system on a national (or supranational) level. However,, cooperation with other stakeholders might be facilitated.

Altogether, digital technologies can be attached and tested far more easily than before, without rearranging the entire IT landscape or being dependent on access to certain information systems or databases. Accordingly, hospitals can more seamlessly explore the potentials of innovative technologies by leaving their routine processes unaffected. However, the HDMP mainly addresses internal barriers (i.e., technological, organizational, behavioral) if implemented, configured, and introduced appropriately, while rather external barriers (i.e., financial, structural, legal) are more difficult to approach technologically. Altogether, hospitals might come closer to attain a state of $\mathrm{OA}$ by leveraging their innovation capacities. Figure 6 consolidates the assessed effects of the HDMP on all identified barriers.

\section{Synthesis phase: Conceptualizing the impact of DI in hospitals}

Once barriers are mitigated, digital innovations might impact hospitals in various ways. Hence, we conducted a multiple case-study analysis (with 36 digital health startups) to explore and conceptualize the potential impact of such innovations. As a result, we specified three different impact dimensions: beneficiaries, areas, and causes. We outline and discuss these dimensions in the following. For each impact dimension, original cases are referred to by "\#” and their number (as per Table 1).
Impact beneficiaries At least three stakeholder groups would benefit from integrating digital innovations. First, this includes the patients who can become safer, healthier or more satisfied. For instance, an app for automatic individual therapeutic exercise plans can improve the recovery (\#24), and a mobile app to support patients with chronic diseases (\#6) can increase satisfaction. Likewise, the usage of a system to record, archive, and analyze long-term ECG (\#15) might even leverage all three effects at once. Second, the staff might also benefit from digital innovations. Here, some innovations enhance their work processes in terms of efficiency (\#5: software to automate the documentation of medical reports), others in terms of effectivity, such as precision (\#18: cyber-physical robotics system to support surgeries). This might in turn increase staff satisfaction. Third, the hospital as an organization might benefit in several ways. From a healthcare perspective, many innovations can help to enhance the healthcare service quality through better treatment or diagnoses (\#27: sensorbased adhesive wearable to monitor patients). From a business perspective, such innovations might improve financial viability (\#25: software to detect accounting errors for medical services) or competitiveness through integrating cutting-edge technologies (\#30: ML-based system for the prognosis of genetic diseases). From a marketing perspective, the innovations can raise patient loyalty and reputation (\#29: healthcare data management and transfer platform for patients). From a more technological point of view, such innovations can enhance security or legal compliance (\#5: software to automate the documentation of medical reports).

Impact areas Digital innovations can affect different areas within the hospital. These include various value creation processes within the hospital supply chain. For one thing, this includes the support processes: Some startups assist the processes of ICT (\#33: P2P technology for secure end-to-end video councils), administration (\#20: health IS for small hospitals with a digital patient record), marketing and customer communication (\#23: app for directly booking consultation appointments), or procurement (\#35: platform to enroll doctors for relevant training courses). For another thing, this includes processes of indirect healthcare. In addition, digital innovations can facilitate various tasks in terms of admission, 


\begin{tabular}{|c|c|c|c|c|c|c|c|}
\hline barrier type & \multicolumn{7}{|c|}{ barrier } \\
\hline technological & interoperability & compatibility & & access & \multicolumn{2}{|c|}{ data access } & complexity \\
\hline organizational & \multicolumn{2}{|c|}{ workflows } & \multicolumn{4}{|c|}{ hierarchy } & culture \\
\hline behavioral & attitude & \multicolumn{2}{|c|}{ acceptance } & \multicolumn{2}{|c|}{ motivation } & & knowledge \\
\hline financial & Rol & \multicolumn{2}{|c|}{ refundability } & \multicolumn{2}{|c|}{ public funds } & & incentives \\
\hline legal & \multicolumn{2}{|c|}{ data/IT security } & \multicolumn{2}{|c|}{ data privacy } & \multicolumn{2}{|c|}{ legal compliance } & data reliability \\
\hline structural & certification & & \multicolumn{2}{|c|}{ approval } & \multicolumn{2}{|c|}{ standardization } & cooperation \\
\hline
\end{tabular}

HDMP impact on barriers: mitigate none

Fig. 6 Assessed effects of the HDMP on digital innovation barriers in hospitals

supply and discharge (\#8: platform for patient pathway automation), anamnesis (\#9: app to capture patient-related outcome measures), care (\#3: mobile app for the patient-nurse communication), and hygiene (\#2: system to control the usage of disinfection agents). Generally, different phases of direct healthcare might be concerned, from prevention (\#7: mobile app for gait pattern analysis to prevent falls) to diagnosis (\#1: mobile app to diagnose deep vein thrombosis), treatment (\#13: platform for psychological online seminars and consultation), aftercare (\#36: monitoring system to support individual home-based aftercare) to rehab (28: gamification-based platform to support therapeutic exercise). What is more, the innovations support the hospital staff (i.e., medical, care, administrative, management) in their daily tasks of planning, execution (\#31: smart exoskeleton to support the lower back of caregivers), decision-making (\#4: software for automating cancer medication plans), and documentation (\#12: mobile app for nurses to automatically record services).

Impact causes Furthermore, we explored the underlying processual and technological causes that entail the abovementioned impact. Generally, work improvement for staff can stem from six impact causes. Some innovations result in a workload reduction or time savings (\#19: chatbot application for patient care; \#12: mobile app for nurses to automatically record services), others allow for more simplification or usability (\#11: health IS plugin to modify or personalize the UI). Additionally, some innovations target emotional factors by improving the work environment (\#26: sensor-based UVtechnology to kill germs) or collaboration at large (\#10: platform and apps for gynecology wards and patients). In addition, the innovations exploit basic IT potentials (Pousttchi et al. 2019a) such as automation (\#24: app for automatic individual therapeutic exercise plans), parallelization (\#15: device and app to record, archive and analyze long-term ECG) or time and space override (\#34: video system to include therapeutic exercises in daily routine). Mostly, a combination of different digital transformation (DT) causes and elements
(Pousttchi 2017; Pousttchi et al. 2019a) is required to leverage the above-mentioned effects.

Among the DT causes, we find processing power, miniaturization, cyber-physical systems (CPS), internet of things (IoT), advanced data-processing techniques, artificial intelligence (AI), and human-computer interaction (HCI). For instance, a mobile app for acoustic feedback on a movement's intensity (\#32) requires local processing power to steer the technology and a compact device with proper sensors (CPS), connectivity (IoT), and human involvement (HCI). Plus, the gathered data needs to be processed, transferred, and analyzed (AI). Among the DT elements, the digital innovations enable ubiquity, telemetry, contextualization, identification, and the exploitation of data. For instance, healthcare data management and transfer platform for patients (\#29) is accessible at any time and from any place (ubiquity), enables the remote control of connected devices and processes such as admission preparation (telemetry), and allows for individual treatment (contextualization) and authorization management of patients and doctors (identification). All services are built on the exploitation of administrative and medical data. Figure 7 synthesizes our findings within impact beneficiaries, areas and causes by means of morphological boxes.

On that basis, we drew on multi-level theory and considered the organizational impact on the hospital and the individual impact on staff and patients from a different perspective (Poole and Van de Ven 1989), which helped us to recognize three further worthwhile findings:

(1) At least two different levels are affected from integrating digital innovations into a hospital's value creation. On a micro level, this includes the patients and individual staff members. On a macro level, this includes the hospital as an organization. This conceptualization might be expanded by other stakeholders such as external companies (e.g., startups, suppliers, cooperation partners) on a macro level and their staff members on a micro level. Plus, 


\begin{tabular}{|l|l|l|l|l|l|l|l|}
\hline beneficiary & \multicolumn{3}{|c|}{ impact } \\
\hline patient & \multicolumn{2}{|c|}{ satisfaction } & \multicolumn{3}{c|}{ healthiness } & \multicolumn{3}{c|}{ effectiveness } \\
\hline staff & \multicolumn{2}{|c|}{ satisfaction } & \multicolumn{3}{c|}{ safety } \\
\hline hospital & service quality & financial viability & reputation & efficiency & legal compliance & patient loyalty & competitiveness \\
\hline
\end{tabular}

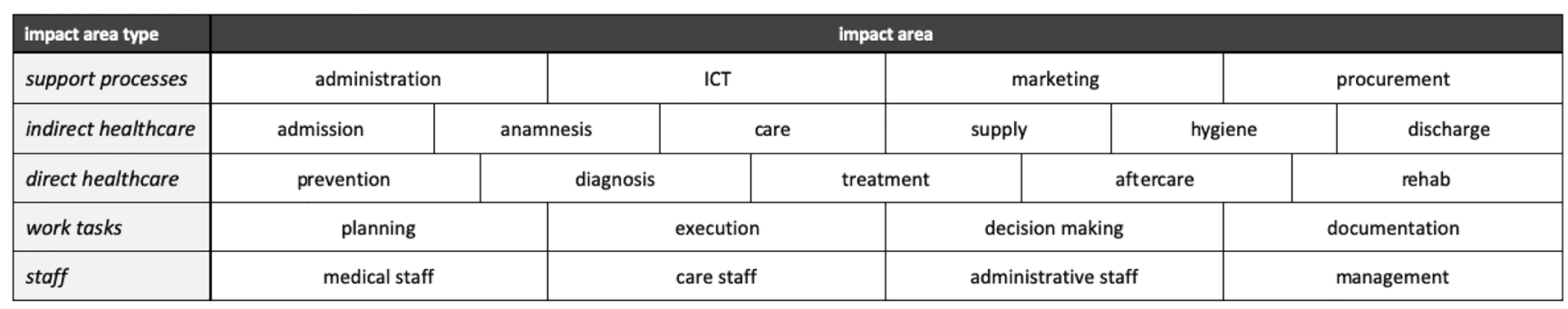

\begin{tabular}{|c|c|c|c|c|c|c|c|}
\hline impact cause type & \multicolumn{7}{|c|}{ impact cause } \\
\hline work environment & workload reduction & usability & simplification & \multicolumn{2}{|c|}{ time savings } & osphere & collaboration \\
\hline IT potentials & automation & information & time override & space override & parallelization & integration & disintermediation \\
\hline DT causes & processing power & miniaturization & CPS & loT & data processing & Al & $\mathrm{HCl}$ \\
\hline DT elements & ubiquity & \multicolumn{2}{|c|}{ telemetry } & contextualization & \multicolumn{2}{|c|}{ identification } & data usage \\
\hline
\end{tabular}

Fig. 7 Set of morphological boxes for impact of digital innovations on hospitals

one could examine the implications beyond hospitals (e.g., healthcare market and system).

(2) Impact causes and areas apply to both levels. For example, individual time savings might ultimately imply time savings at an organizational level, and a patient can use IoT-based devices or CPS, which in turn might enhance patient monitoring and management for the hospital in its entirety. The same applies to impact areas. For instance, a digital innovation might likewise enhance decisionmaking on both an individual (e.g., decision support tool) and an organizational level (e.g., decision coordination tool).
(3) Thus, we can assume several interdependencies between both levels. For instance, an improved healthcare service quality by the hospital might implicate an increased patient healthiness and satisfaction, which in turn improves the hospital's reputation, competitiveness, and patient loyalty. Similarly, increased staff effectiveness and efficiency might positively affect the hospital's overall performance. Altogether, even if the HDMP might help to mitigate (especially technological) barriers, the socioeconomic interdependencies still have to be evaluated carefully. Figure 8 condenses our findings into a conceptual framework.
Fig. 8 Multi-level framework of digital innovation impact on hospitals

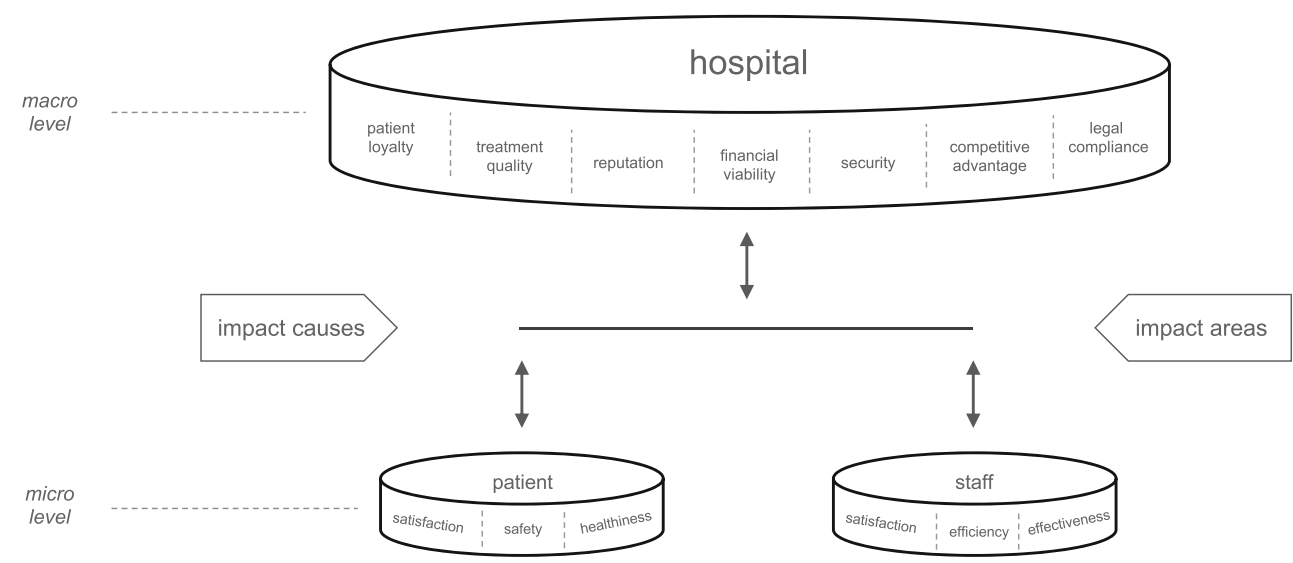




\section{Conclusion}

The starting point of our research endeavor was the notion that hospitals often lack a strategic approach of integrating innovative digital technologies to improve their value-creating capacities, while a multitude of digital innovations from digital health startups enters the promising healthcare market. Against this background, we sought to explore how hospitals could more easily integrate digital healthcare innovations through an HDMP in order to approach OA. Our results are threefold: First, we provide a systematic overview of literature-based and practically validated barriers for digital health innovations in hospitals. Second, we provide an assessment of how an HDMP might help mitigate such barriers. Third, we conceptualized the potential impact of the integration of digital innovations in hospitals from a multi-level perspective. Our findings reveal that an HDMP helps hospitals to raise their innovative capacities through ambidextrous structures. Especially, it can help to mitigate technological (connect or integrate new technologies), organizational (workflows and culture), and behavioral barriers (as acceptance and motivation). However, such a platform alone cannot solve all problems of sourcing digital technologies, particularly in terms of externally induced barriers, such as legal or structural ones. Thus, there might be complementary and less technology-oriented approaches to surmount barriers for innovation (e.g., change management).

As a contribution to research, we added another puzzle piece into the emerging field of digital health by applying a sociotechnological lens to the healthcare domain. Therefore, we provide a systematic understanding of potential barriers and impact potentials of integrating digital innovations in hospitals. Additionally, we show how an HDMP might help hospitals approach $\mathrm{OA}$ and extract advantages from new technologies by overcoming such barriers. The conceptual framework provides a first structured overview of potential innovative capacities of digital health projects in hospitals at both organizational and individual levels, including generalized assumptions of the relationships. As a contribution to practice, we sensitize about barriers digital innovations typically face, present a solution to mitigate such barriers, and provide an overview of potential benefits to capture. Thus, healthcare practitioners might employ this overview to systematically evaluate their IT landscapes and the potential benefits of new technologies.

By its qualitative nature, our research entails several limitations. While the identified literature-based barriers might be comprehensive and inherently logical, other researchers might have coded and derived other items and classes. The same applies to the impact types, which result from the deductively selected and applied concepts as well as the selection of considered cases. Furthermore, the assessment of the mitigated barriers is a subjective view on the observed clinic group in our case. Hence, these findings are only partly generalizable. We see two avenues for future research. From a technological standpoint, research could design options that promote interoperability among existing and new technologies. From a socio-technological standpoint, research could zero in on the interplay of different actors at multiple levels, which hamper or foster digital innovations in hospitals. Especially, the interdependencies and relationships among all levels should be elaborated, both qualitatively and quantitatively.

Abbreviations $B 2 B / B 2 C$, Business-to-business/customer; $C A S$, Content-addressed storage; $C E O$, Chief executive officer; $C I O$, Chief information officer; $C S V$, Comma separated values; $D I$, Digital innovation; DICOM, Digital imaging and communications in medicine; DMS, Data management system; $D T$, Digital transformation; $E C F$, Electronic case file; $E C G$, Electrocardiogram; FTP, File transfer protocol; ERP, Enterprise resource planning; $H D M P$, Hospital data management platform; HIN ACS, HIN access control system (Swiss communication standard); HIS, Health/hospital information system; $H L 7$, Health level 7; $\operatorname{HTTP}(S)$, Hypertext transfer protocol (secure); ICT, Information and communication technologies; IMAP, Internet message access protocol; $I H E$, Integrating the healthcare enterprise; ILM, Information lifecycle management; IS, Information system(s); IT, Information technologies; $L D A P$, Lightweight directory access protocol; $L I S$, Laboratory information system; $M L$, Machine learning; MPI, Master patient index; NAS, Network-attached storage; NFS, Network file system; $O A$, Organizational ambidexterity; $O C R$, Optical character recognition; $P 2 P$, Peer-to-peer; $P A C S$, Picture archiving and communication system; $P D F$, Portable document format; PDMS, Patient data management system; REST, Representational state transfer; RIS, Radiology information system; RoI, Return on investment; SAN, Storage area network; SAP HCM, SAP human capital management (ERP module); UI, User interface; $U V$, Ultraviolet light; $X M L$, Extensible markup language; WORM, Write once, read many

Authors' contributions All authors contributed to the study conception and design. Material preparation, data collection and analysis of literature review and startup interviews was performed by Stefanie Lewandowski. Material preparation, data collection and analysis of theoretical background, project and focus group interview was performed by Alexander Gleiss. The first draft of the manuscript was written by Alexander Gleiss and all authors commented on previous versions of the manuscript. All authors read and approved the final manuscript.

Funding Open Access funding enabled and organized by Projekt DEAL.

Data availability The following data and material can be requested from the corresponding author: literature review data; notes from interviews with startups (German); notes from focus group interview with HealthEngine provider and users (German).

Code availability Not applicable.

\section{Declarations}

Conflict of interest The authors declare that they have no conflict of interest.

Ethics approval Not applicable.

Consent to participate Not applicable.

Open Access This article is licensed under a Creative Commons Attribution 4.0 International License, which permits use, sharing, adaptation, distribution and reproduction in any medium or format, as long as 
you give appropriate credit to the original author(s) and the source, provide a link to the Creative Commons licence, and indicate if changes were made. The images or other third party material in this article are included in the article's Creative Commons licence, unless indicated otherwise in a credit line to the material. If material is not included in the article's Creative Commons licence and your intended use is not permitted by statutory regulation or exceeds the permitted use, you will need to obtain permission directly from the copyright holder. To view a copy of this licence, visit http://creativecommons.org/licenses/by/4.0/.

\section{References}

Aanestad M, Vassilakopoulou P, Øvrelid E (2019) Collaborative innovation in healthcare: boundary resources for peripheral actors. In: ICIS 2019 Proceedings. Munich, Germany

Abraham C, Junglas I (2011) From cacophony to harmony: a case study about the IS implementation process as an opportunity for organizational transformation at Sentara healthcare. J Strategic Inform Syst 20:177-197. https://doi.org/10.1016/j.jsis.2011.03.005

Agarwal R, Gao G(G), DesRoches C, Jha AK (2010) Research commentary - the digital transformation of healthcare: current status and the road ahead. Inform Syst Res 21:796-809. https://doi.org/10. 1287/isre. 1100.0327

Ajami S, Arab-Chadegani R (2013) Barriers to implement electronic health records (EHRs). Mater Sociomed 25:213-215. https://doi. org $/ 10.5455 / \mathrm{msm} .2013 .25 .213-215$

Akhlaq A, McKinstry B, Muhammad KB, Sheikh A (2016) Barriers and facilitators to health information exchange in low- and middleincome country settings: a systematic review. Health Policy Plan 31:1310-1325. https://doi.org/10.1093/heapol/czw056

Ambigavathi M, Sridharan D (2018) Big Data Analytics in Healthcare. In: 2018 ICoAC Proceedings. Chennai, India

Anderson JG (2007) Social, ethical and legal barriers to e-health. Int J Med Inform 76:480-483. https://doi.org/10.1016/j.ijmedinf.2006. 09.016

Apathy NC, Holmgren AJ (2020) Opt-in consent policies: potential barriers to hospital health information exchange. Am J Manag Care 26: e14-e20. https://doi.org/10.37765/ajmc.2020.42148

Barney JB (2001) Is the resource-based "view" a useful perspective for strategic management research? Yes. AMR 26:41-56. https://doi. org/10.5465/amr.2001.4011938

Benbasat I, Goldstein DK, Mead M (1987) The case research strategy in studies of information systems. MIS Q 11:369-386. https://doi.org/ $10.2307 / 248684$

Bergman B, Neuhauser D, Provost L (2011) Five main processes in healthcare: a citizen perspective. BMJ Quality Safety 20:i41-i42. https://doi.org/10.1136/bmjqs.2010.046409

Blobel B, Ruotsalainen P (2019) How does GDPR support healthcare transformation to 5P medicine? MEDINFO: 1135-1139. https:// doi.org/10.3233/SHTI190403

Bodwell W (2011) A theoretical model of organizational ambidexterity in hospitals. Colorado State University, Fort Collins

Bogdan B (2018) MedRevolution: Neue Technologien am Puls der Patienten. Springer, Berlin

Bradley RV, Pratt RME, Byrd TA, Outlay CN, Jr DEW (2012) Enterprise architecture, IT effectiveness and the mediating role of IT alignment in US hospitals. Inform Syst J 22:97-127. https://doi.org/10.1111/j. 1365-2575.2011.00379.x

Brown C, Jensen TB, Winkler TJ, Aanestad M, Currie W, Pigni F, Shahar Y (2014) Leveraging digital innovation in healthcare: harnessing big data, cloud and mobile computing for better health. In: ECIS 2014 Proceedings. Tel Aviv, Israel, p 7
Brucher L, Mosel K, Pontet K, Georges A (2018) A journey towards smart health. Deloitte Tax \& Consulting. https:/www2.deloitte. $\mathrm{com} / \mathrm{lu} / \mathrm{en} /$ pages/life-sciences-and-healthcare/articles/journeytowards-smart-health.html

Burgess N, Strauss K, Currie G, Wood G (2015) Organizational ambidexterity and the hybrid middle manager: the case of patient safety in UK hospitals. Hum Resour Manag 54:s87-s109. https://doi.org/ 10.1002/hrm. 21725

Bygstad B, Hanseth O, Siebenherz A, Øvrelid E (2017) Process innovation meets digital infra-stucture in high-tech hospital. In: ECIS 2017 Proceedings. Guimarães, Portugal, pp 801-814

Chan Y, Dekker A, Ramsden D (2004) Diffusing healthcare innovations: a case study of the care delivery network. AMCIS 2004 Proceedings. 29.https://aisel.aisnet.org/amcis2004/29

Chowdhury J (2012) Hacking health: bottom-up innovation for healthcare. TIM - Technology Innovation Management Review. 2(7):31-35. https://doi.org/10.22215/timreview/579.

Christensen C, Waldeck A, Fogg R (2017) How disruptive innovation can finally revolutionize healthcare. Innosight \& The Christensen Institute. https://www.christenseninstitute.org/publications/howdisruption-can-finally-revolutionize-healthcare/

Cooper HM (1988) Organizing knowledge syntheses: a taxonomy of literature reviews. Knowledge in Society 1:104-126. https://doi. org/10.1007/BF03177550

Dash DP, Henricson C, Kumar DP, Stern N (2019) The hospital is dead, long live the hospital! London. https:/www.mckinsey.com/ industries/healthcare-systems-and-services/our-insights/thehospital-is-dead-long-live-the-hospital

Denner M-S, Püschel LC, Röglinger M (2018) How to exploit the digitalization potential of business processes. Bus Inf Syst Eng 60:331349. https://doi.org/10.1007/s12599-017-0509-x

Desveaux L, Soobiah C, Bhatia RS, Shaw J (2019) Identifying and overcoming policy-level barriers to the implementation of digital health innovation: qualitative study. J Med Internet Res 21:e14994. https:// doi.org/10.2196/14994

Donaldson T, Preston LE (1995) The stakeholder theory of the corporation: concepts, evidence, and implications. Acad Manag Rev 20:6591. https://doi.org/10.2307/258887

Duncan RB (1976) The ambidextrous organization: designing dual structures for innovation. In: Kilmann RH, Pondy LR, Slevin DP (eds) The management of organization design: Strategies and implementation. North Holland, New York, pp 167-188

Eddy N (2020) Providers struggling to give patients useful digital tools. In: Healthcare IT News. https://www.healthcareitnews.com/news/ providers-struggling-give-patients-useful-digital-tools. Accessed 8 Mar 2020

Fernández E (2017) Innovation in healthcare: harnessing new technologies. JMWAIS 2017:107-120. https://doi.org/10.17705/3jmwa. 00034

Fichman RG, Kohli R, Krishnan R (eds) (2011) Editorial overview-the role of information Systems in Healthcare: current research and future trends. Inform Syst Res 22:419-428. https://doi.org/10. 1287/isre. 1110.0382

Fiechter V, Meier M (1998) Pflegeplanung: eine Anleitung für die Praxis, 10th edn. Recom, Basel

Frederix I, Caiani EG, Dendale P, Anker S, Bax J, Böhm A, Cowie M, Crawford J, de Groot N, Dilaveris P, Hansen T, Koehler F, Krstačić G, Lambrinou E, Lancellotti P, Meier P, Neubeck L, Parati G, Piotrowicz E, Tubaro M, van der Velde E (2019) ESC ecardiology working group position paper: overcoming challenges in digital health implementation in cardiovascular medicine. Eur $\mathrm{J}$ Prev Cardiolog 26:1166-1177. https://doi.org/10.1177/ 2047487319832394

Gagnon MP, Desmartis M, Labrecque M, Car J, Pagliari C, Pluye P, Frémont P, Gagnon J, Tremblay N, Légaré F (2012) Systematic review of factors influencing the adoption of information and 
communication technologies by healthcare professionals. J Med Syst 36:241-277. https://doi.org/10.1007/s10916-010-9473-4

Gajarawala SN, Pelkowski JN (2020) Telehealth benefits and barriers. J Nurse Pract S1555415520305158. https://doi.org/10.1016/j.nurpra. 2020.09 .013

Garbuio M, Lin N (2019) Artificial intelligence as a growth engine for health care startups: emerging business models. California Manag Rev 61:59-83. https://doi.org/10.1177/0008125618811931

Gersch M, Wessel L (2019) E-Health \& Health-IT. Encyclopedia of Business Informatics

Ghosh K, Dohan M, Veldandi H (2018) Digital transformation strategies for healthcare providers: perspectives from senior leadership. In: AMCIS 2018 Proceedings, New Orleans

Gibson CB, Birkinshaw J (2004) The antecedents, consequences, and mediating role of organizational ambidexterity. Acad Manag J 47: 209-226. https://doi.org/10.2307/20159573

Gimpel DH, Röglinger DM (2015) Digital transformation. fraunhofer institute for applied information technology (FIT), Augsburg/ Bayreuth

Gleiss A (2020) The patient will see you now - Towards an understanding of on-demand healthcare. In: 2020 IEEE 22nd Conference on Business Informatics (CBI). IEEE, Antwerp, Belgium, pp 154-161. https://doi.org/10.1109/CBI49978.2020.00024

Gleiss A, Kohlhagen M, Pousttchi K (2021) An apple a day - how the platform economy impacts value creation in the healthcare market. Electronic Markets (in press). https://doi.org/10.1007/s12525-02100467-2

Graetz I (2020) The health IT special issue: enduring barriers to adoption and innovative predictive methods. Am J Manag Care 26:19. https:// doi.org/10.37765/ajmc.2020.42140

Greenhalgh T, Robert G, Macfarlane F, Bate P, Kyriakidou O (2004) Diffusion of innovations in service organizations: systematic review and recommendations. Milbank Q 82:581-629. https://doi.org/10. 1111/j.0887-378X.2004.00325.X

Grisot M, Thorseng A, Hanseth O (2013) Staying Under the Radar: Innovation Strategy in Information Infrastructures for Health. In: ECIS 2013 Proceedings. Utrecht, The Netherlands

Gurtner S (2014) Modelling consumer resistance to mobile health applications. In: ECIS 2014 Proceedings. Tel Aviv, Israel

Hammer M, Champy J (1993) Reengineering the corporation: a manifesto for business revolution. Harper Business, New York

Harst L, Timpel P, Otto L, Richter P, Wollschlaeger B, Winkler K, Schlieter H (2019) Identifying barriers in telemedicine-supported integrated care research: scoping reviews and qualitative content analysis. J Public Health 28:583-559. https://doi.org/10.1007/ s10389-019-01065-5

Holden RJ, Karsh B-T (2010) The technology acceptance model: its past and its future in health care. J Biomed Inform 43:159-172. https:// doi.org/10.1016/j.jbi.2009.07.002

Hund A, Drechsler K, Reibenspiess VA (2019) The current state and future opportunities of digital innovation: a literature review. In: ECIS 2019 Proceedings. Stockholm-Uppsala, Sweden

Hussainy SF, Zaffar F, Zaffar MA, Khaliq A, Khan IH (2017) Decisiontree inspired classification algorithm to detect Tuberculosis (TB). PACIS 2017 Proceedings Pacific Asia Conference on Information Systems (PACIS):

Islam N, Buxmann P, Ding D (2017) Fostering digital innovation through inter-organizational collaboration between incumbent firms and start-ups. In: ECIS 2017 Proceedings. Guimarães, Portugal

Kizito M, Kahiigi E (2018) Conflicting logics in IT Governance: Achieving ambidexterity in healthcare organisations. In: AMCIS 2018 Proceedings, New Orleans

Knöppler K, Neisecke T, Nölke L (2016) Digital-Health-Anwendungen für Bürger: Kontext, Typologie und Relevanz aus Public-HealthPerspektive. https://www.bertelsmann-stiftung.de/fileadmin/files/
BSt/Publikationen/GrauePublikationen/Studie_VV_Digital-HealthAnwendungen_2016.pdf. Accessed 14 Mar 2020

Kohler T (2016) Corporate accelerators: building bridges between corporations and startups. Business Horizons 59:347-357. https://doi.org/ 10.1016/j.bushor.2016.01.008

Kohli R, Melville NP (2019) Digital innovation: A review and synthesis. Info Systems J 29:200-223. https://doi.org/10.1111/isj.12193

Koster F, van Bree G (2018) How managers evoke ambidexterity and collaboration: a qualitative study in a Dutch hospital. Int J Innovat Technol Manage 15:1850049. https://doi.org/10.1142/ S0219877018500499

Kwak C, Lee J, Lee H (2016) Effects of information technology on team innovation and inter-team coordination: an exploratory investigation of process ambidexterity. In: 2016 49th Hawaii international conference on system sciences (HICSS). IEEE, Koloa, pp 5309-5318

Lapāo L (2019) The future of healthcare: the impact of digitalization on healthcare services performance. In: The internet and health in Brazil - challenges and trends. Springer, Cham, pp 435-449

Lim SY, Anderson EG (2016) Institutional barriers against innovation diffusion: from the perspective of digital health startups. In: 2016 49th Hawaii international conference on system sciences (HICSS). IEEE, Koloa, pp 3328-3337

Lluch M (2011) Healthcare professionals' organisational barriers to health information technologies - a literature review. Int J Med Inform 80:849-862. https://doi.org/10.1016/j.ijmedinf.2011.09.005

MacNeil M, Koch M, Kuspinar A, Juzwishin D, Lehoux P, Stolee P (2019) Enabling health technology innovation in Canada: barriers and facilitators in policy and regulatory processes. Health Policy 123:203-214. https://doi.org/10.1016/j.healthpol.2018.09.018

Malekzadeh S, Hashemi N, Sheikhtaheri A, Hashemi N-S (2018) Barriers for implementation and use of health information systems from the physicians' perspectives. - abstract - Europe PMC. In: Data, informatics and technology: an inspiration for improved healthcare. IOS Press, Amsterdam

Mandl KD, Mandel JC, Kohane IS (2015) Driving innovation in health systems through an apps-based information economy. Cell Systems 1:8-13. https://doi.org/10.1016/j.cels.2015.05.001

Mason P, Mayer R, Chien W-W, Monestime JP (2017) Overcoming barriers to implementing electronic health Records in Rural Primary Care Clinics. Qual Rep 22:2943-2955

Mayring P (2000) Qualitative content analysis. Forum Qualitative Social Res 1

McLachlan S, Dube K, Johnson O, Buchanan D, Potts HWW, Gallagher T, Fenton N (2019) A framework for analysing learning health systems: Are we removing the most impactful barriers? Learn Health Sys 3. https://doi.org/10.1002//rh2.10189

Menvielle L, Audrain-Pontevia A-F, Menvielle W (2017) The digitization of healthcare: new challenges and opportunities. Palgrave Macmillan, London

Miscione G (2007) Telemedicine in the upper Amazon: interplay with local health care practices. MIS Q 31:403-425. https://doi.org/10. 2307/25148797

Mohamadali NA, Zahari NA (2017) The organization factors as barrier for sustainable health information systems (HIS) - a review. Procedia Comput Sci 124:354-361. https://doi.org/10.1016/j. procs.2017.12.165

Montealegre R, Iyengar K, Sweeney J (2019) Understanding Ambidexterity: Managing Contradictory Tensions Between Exploration and Exploitation in the Evolution of Digital Infrastructure. JAIS 647-680. https://doi.org/10.17705/1jais.00547

Nohl-Deryk P, Brinkmann J, Gerlach F, Schreyögg J, Achelrod D (2018) Hürden bei der Digitalisierung der Medizin in Deutschland (Barriers for Digitalization in the German Medicine Sector). Gesundheitswesen 80:939-945. https://doi.org/10.1055/s-0043121010 
O'Reilly CAO, Tushman ML (2004) The Ambidextrous Organization. Havard Business Review

Otto L, Harst L (2019) Investigating Barriers for the Implementation of Telemedicine Initiatives: A Systematic Review of Reviews. In: AMCIS 2019 Proceedings. Cancun, Mexico, p 10

Palacholla RS, Fischer N, Coleman A, Agboola S, Kirley K, Felsted J, Katz C, Lloyd S, Jethwani K (2019) Provider- and patient-related barriers to and facilitators of digital health technology adoption for hypertension management: scoping review. JMIR Cardio 3:e11951. https://doi.org/10.2196/11951

Patton MQ (2015) Qualitative Research \& Evaluation Methods: integrating theory and practice, 4th edn. Sage, Thousand Oaks

Poole MS, Van de Ven AH (1989) Using paradox to build management and organization theories. Acad Manag Rev 14:562-578. https:// doi.org/10.2307/258559

Porter ME (1985) Competitive advantage: creating and sustaining superior performance. Simon and Schuster, New York

Pousttchi K (2017) Digital Transformation. Encyclopedia of Business Informatics. https://www.enzyklopaedie-der-wirtschaftsinformatik. de/lexikon/technologien-methoden/Informatik\%2D\% 2DGrundlagen/digitalisierung/digitale-transformation/digitaletransformation. Accessed 8 Mar 2020

Pousttchi K, Gleiss A, Buzzi B, Kohlhagen M (2019a) Technology impact types for digital transformation. In: IEEE 21 st conference on business informatics (CBI). IEEE, Moscow, pp 487-494. https:// doi.org/10.1109/CBI.2019.00063

Pousttchi K, Schlieter H, Gleiss A (eds) (2019b) Digitale Innovationen im Gesundheitsmarkt (digital innovations in healthcare). GITO, Berlin

Przybilla L, Klinker K, Wiesche M, Krcmar H (2018) A Human-Centric Approach to Digital Innovation Projects in Health Care: Learnings from Applying Design Thinking. In: PACIS 2018 Proceedings. https://aisel.aisnet.org/pacis2018/226/

Raisch S, Birkinshaw J (2008) Organizational ambidexterity: antecedents, outcomes, and moderators. J Manag 34:375-409. https://doi. org/10.1177/0149206308316058

Ritchey T (2013) General Morphological Analysis

Rothaermel FT, Alexandre MT (2009) Ambidexterity in technology sourcing: the moderating role of absorptive capacity. Organization Sci 20:759-780. https://doi.org/10.1287/orsc.1080.0404

Sahay S, Nielsen P, Faujdar D, Kumar R, Mukherjee A (2018) Frugal digital innovation and living labs: a case study of innovation in public health in India. In: ICIS 2018 Proceedings, San Francisco

Scheplitz T, Kaczmarek S, Benedict M (2019) The critical role of hospital information systems in digital health innovation projects. In: IEEE 21 st conference on business informatics (CBI). IEEE, Moscow, pp 512-521

Schubert P (2004) Case Study Triamun: solving IT integration problems in the health care sector with the innovative use of an ASP software solution. In: AMCIS 2004 Proceedings, New York

Shen T-W, Liu F-C, Chen WS-T (2013) Developing non-parametric density estimation on genetic evolution computing as a cloud-based sensor fusion method: taking psychiatric major depressive disorder detection as an application example. In: 2013 seventh international conference on sensing technology (ICST). IEEE, Wellington, pp 56-61

Soobiah C, Desveaux L, Bhatia S, Shaw J (2020) Identifying and overcoming policy level barriers to the implementation of digital health innovation in Ontario: qualitative study. Health Serv Res 55:112113. https://doi.org/10.1111/1475-6773.13491

Stamatian F, Baba CO, Timofe MP (2013) Barriers in the implementation of health information systems: a scoping review. Transylvanian Rev Administrat Sci Special Issue :156-173. https://rtsa.ro/tras/index. $\mathrm{php} /$ tras/article/view/404/0

Steinhauser S (2019) Network-based business models, the institutional environment, and the diffusion of digital innovations: case studies of telemedicine networks in Germany. Schmalenbach Bus Rev 71: 343-383. https://doi.org/10.1007/s41464-019-00076-9

Sunyaev A, Dünnebeil S, Mauro C, Leimeister J-M, Krcmar H (2010) ITStandards im Gesundheitswesen: Überblick und Entwicklungsperspektiven mit der Einführung Service-Orientierter Architekturen. In: Informatik 2010 Service Science - Neue Perspektiven für die Informatik, Leipzig

Tarafdar M, Gordon SR (2007) Understanding the influence of information systems competencies on process innovation: a resource-based view. J Strategic Inform Syst 16:353-392. https://doi.org/10.1016/j. jsis.2007.09.001

Teoh SY (2010) A case study of healthcare information technology implementation: agile-innovative capability development process. In: PACIS 2010 Proceedings. https://aisel.aisnet.org/pacis2010/27/

Thambusamy R, Palvia P (2011) IT-based capabilities, service innovation, and quality in health care. In: 32 nd International Conference on Information Systems (ICIS). Shanghai, China

Vannieuwenborg F, Verbrugge S, Colle D (2015) Integrating digital health services: the role of the government and the challenge of cost allocation. In: 2015 17th international conference on E-health networking, Application \& Services (HealthCom). IEEE, Boston, pp $81-85$

Villegas S (2019) 10 European medtech startups revolutionising healthcare. In: EU-Startups. https://www.eu-startups.com/2019/08/ 10-european-medtech-startups-revolutionizing-healthcare/. Accessed 8 Mar 2020

vom Brocke J, Buddendick C, Kelly S, Peadar ÓS (2007) The design and evaluation of a clinical process mapping methodology (CPMM) to support information systems (IS) innovation in a healthcare context. In: BLED 2007 Proceedings. Bled, Slovakia, p 14

Webster J, Watson RT (2002) Guest editorial: analyzing the past to prepare for the future: writing a literature review. MIS Q 26:xii-xxiii

Williams M (2019) The digital hospital of the future: it doesn't start with tech. In: InfoGoTo. https://www.infogoto.com/the-digital-hospitalof-the-future-it-doesnt-start-with-tech/. Accessed 8 Mar 2020

Wolf V (2019) Ambidextertiy in Service Innovation Research. In: 14th Wirtschaftsinformatik 2019 Proceedings. Siegen, Germany

Wolf V, Lüttenberg H (2020) Capabilities for ambidextrous innovation of digital service. In: 15th Wirtschaftsinformatik 2020 Proceedings. Potsdam, Germany

Xie W, Palvia P, Vance L (2019) Value co-creation and challenges in electronic health record (EHR). In: 40th International Conference on Information Systems (ICIS). Munich, Germany

Yin RK (2009) Case study research: design and methods, 4th edn. Sage, Los Angeles

Yoo Y, Henfridsson O, Lyytinen K (2010) The new organizing logic of digital innovation: an agenda for information systems research. Inform Syst Res 21:724-735. https://doi.org/10.1287/isre.1100. 0322

Yoo Y, Boland RJ, Lyytinen K, Majchrzak A (2012) Organizing for innovation in the digitized world. Organization Sci 23:1398-1408. https://doi.org/10.1287/orsc.1120.0771

Zaidan BB, Zaidan AA, Mat Kiah ML (2011) Impact of data privacy and confidentiality on developing telemedicine applications: a review participates opinion and expert concerns. Int J Pharmacol 7:382-387

Zakaria N, Mohd Yusof SA (2016) Understanding technology and people issues in hospital information system (HIS) adoption: case study of a tertiary hospital in Malaysia. J Infect Public Health 9:774-780. https://doi.org/10.1016/j.jiph.2016.08.017

Zwicky F (1966) The morphological method (Entdecken, Erfinden, Forschen im Morphologischen Weltbild), 2nd edn. DroemerKnaur, München

Publisher's note Springer Nature remains neutral with regard to jurisdictional claims in published maps and institutional affiliations. 